\title{
Attitudes of Tourists about the Possibility of Development of Unusual Hotels in Serbia
}

\author{
Klisara Dubravka, Bradić Milan, Balaž Melita* \\ Received: June 2014 | Accepted: November 2014
}

\section{Abstract}

This paper deals with the problem of relatively young type of hotel that is increasingly attracting the attention of the modern tourist. Unusual hotels are very interesting phenomenon, not only for tourists and hospitality professionals, but also for people who are (currently) out of the tourist flows. These are facilities with untypical architectural design, non-standard equipped or with services that are not common in the hospitality industry. They often contribute to the attractiveness of the area in which they are located. However, business sustainability of unusual hotels, as well as any other hotel, depends on guests, i.e. number of overnight stays.

We present the results of research conducted among tourists in Serbia. The main task is to examined whether tourists are interested in the potential developing of unusual hotels. If so, which subtypes of unusual hotel would be best suited for the territory of Serbia. In order to compare experiences and operating results, parallel survey was conducted among owners of unusual hotels around the world.

The results suggest a conclusion - with a favourable investment climate, unusual hotels should have a future in Serbia.

Key words: tourism, hospitality, hotel industry, unusual hotels, hotel development, market research

\section{Introduction}

Unusual hotels offer guests an atypical stay. Basic services are the same as in traditional hotels, but in each of them there is the factor that sets it apart from other hotels. That factor is reflected in locations, materials of which they are constructed, interior and exterior decoration, services offered, the way in which services are provided and so on. From the perspective of tourists unusual hotels represent a completely new form of accommodation than usual, a new experience, which is certainly not easy to forget.

Tourism practice around the world has shown that these hotels can be standalone motivators for travelling to various locations that may not have other tourist values. On the other

* University of Novi Sad, Faculty of Sciences, Department of Geography, Tourism and Hotel Management, Trg Dositeja Obradovića 3, 21000 Novi Sad, Serbia, Corresponding author: milanbradic@gmail.com 
hand, sites that have other tourist values become more attractive if they have this type of hotel. It follows that the concept of an unusual hotel is convenient to almost all locations, regardless of the current value of tourism environment (Keiser, 1998; Gray, et al., 200o; Dalbor, Upneja, 2004). In this study we will discuss whether unusual hotels, in the opinion of tourists, will be able to find their place in Serbian tourism market.

This type of research has never been done in Serbia. In this paper we studied some of unusual hotels around the world, in Serbia's surrounding, and in territory of Serbia. In addition, it will be presented and analyzed the results of research among tourists and their interest and opinion on the possibility of developing unusual hotels in Serbia.

To achieve the aim, the authors had to perform several tasks: to check whether there are any unusual hotels in Serbia, to make sure that in the neighbouring countries there are unusual hotels and how they operate, to collect data on the operations of these facilities on a global level, to identify interest of domestic tourists in this type of accommodation, and to analyze the results and to draw conclusions.

\section{The definition of hotel and typification}

Many theorists and practitioners have dealt with defining the hotel. Among them we should mention Alfred Walterspiel (Walterspiel, 1952), Roger Doswell (Doswell, Nailon, 1976), Victor Middleton (Middleton, 1988). As a result, there were a number of definitions, but common elements of all of them reefer to emphasize the special hotel service including: higher class of accommodation, meeting the demands of modern travellers, highlighting accommodation services, high levels of staff competence, insisting on complete hotel service.

According to American literature, the word "Hotel" derives from the Latin word "Hospitas", which means hospitality. The French definition of this word is associated with urban residence of the wealthy and prominent personalities. One thing is certain, the word "Hotel" is well known throughout Europe and the world, the term has been accepted as an international name. In Serbian terminology hotel is a facility which provides accommodation, food and drink and other services common in the hospitality industry (Janicevic, 2008).

The following conceptual definition should provide a comprehensive picture of the term "hotel": "The hotel is basic, representative accommodation facility, intended for different categories of users, which operates on commercial principles, in technological, organizational and personnel terms capable to provide accommodation service, integrated with food and drinks service, including the provision of additional services, functionally connected in integral product" (Kosar, 2008a).

All hotels comprise one kind of hospitality establishment. However, there is also separation of certain types of hotels as integral component of the development of hotel activities. The existence of different types of hotels indicates a higher level of hotel development. "Typification is the process of separation of different forms of hotel industry offer, based on various criteria" (Kosar, 2008b).

Typification of the hotels is done in relation to four main factors: location (coastal hotel, mountain hotel, spa hotel, city hotel, transit hotel), motive of stay (resort hotel, business hotel, conference hotel, convention hotel, casino hotel...), categories of consumers (sports hotel, wellness hotel, family hotel...), way of designing and furnishing (condo hotels, boutique hotels, design hotels, HIP hotels, theme hotels, eco hotels, destination hotels). However it should be noted that one cannot draw a sharp line between the individual factors of typification - same hotel can belong to different types. 


\section{Unusual hotels}

In literature, the term "unusual hotel" is often equated with the term "boutique hotel" which is a mistake (Liana, et al., 2005; Wai, Mel, 2009). These two types of hotel may have some similarities, but this is not the rule (Mandy, 2007).

The most general definition of "boutique hotel" emphasizes that it is especially designed and styled hotel type of small capacity, usually high-class, situated in an attractive location with a special focus on personalized service (Hakan, 2006).

On the other hand, "unusual hotel" is a type of hotels that were built in uncommon locations, with unusual architectural design and/or have complex of services (or way of providing services) which is not common in the hospitality industry.

By comparing these two definitions, we can see a clear difference between them. With a boutique hotel, the emphasis is on style and personalization, while unusual hotels tend eccentricity and uniqueness. This type of hotel is a unique synthesis of elements and criteria that determine a boutique, design, theme and destination hotels.

Further division of unusual hotels in the subtypes is conducted thanks to the combination of various criteria. Many Web sites that deal with unusual hotels have their own subtypes, but the most comprehensive is the division by Lj. Kosar (Kosar, 2008b). It is possible to sort out, not be limited to, 19 varieties of unusual hotels (with examples):

1. Museums and galleries (Rezidenza D'Arte, Italia)

2. Castles and fortresses (Le Prince Noir, France)

3. Unusually designed (Palacio de Sal, Bolivia)

4. Desert oasis (Desert Palm resort, UAE)

5. Eco-resorts (Verana, Mexico)

6. Imaginative thematic (Pelirocco, Germany)

7. Cottages, tents, cabins (Das Park Hotel, Austria)

8. Historical-religious (Martin's Patershof, Belgium)

9. Ice-igloos (Iglu-Dorf, Switzerland)

10. Islands (Taj lake palace, India)

11. Vehicles (Controversy Hotel, Netherlands)

12. Lighthouses (Heceta Head Lightstation, USA)

13. Prisons (Karosta Prison, Latvia)

14. Hotels located in the tropical forests, jungles, bushes (Sapory, India)

15. Tree houses (Kadir's Tree Houses, Turkey)

16. Underground-Caves (Becham Cave, USA)

17. Underwater (Poseidon Undersea Resort, Fiji)

18. Belvederes (The Marmara Antalya, Turkey)

19. Children (Dog Bark Park Inn, USA) and so on.

\section{Methodology}

The initial phase of the research included a comparative analysis of unusual hotels globally, in the region and in Serbia itself.

The main study included data collection via two different questionnaires. The first questionnaire was designed to examine the business of unusual hotels around the world. This study was conducted using e-mail. Of particular use were the best known websites about unusual 
hotels. Website www.unusualhotels.com combines unusual hotels from around the world in one place and give a brief description along with the ability to send a query for the desired period of stay. We should mention other internet sites of this type, www.weirdandwonderfulhotels. com and www.escapenormal.com.

The questionnaire for the owners of unusual hotels consists of eight questions. Questionnaires were sent to 100 addresses all over the world, and arrived (only) 20 correctly filled. Due to the small number of responses, any detailed statistical analysis was not possible, but the resulting data could provide some conclusions. Consequently, the results of this survey will be presented here in order to provide qualitative results.

The second questionnaire was designed for respondents (tourists) in the territory of the Republic of Serbia in order to explore their views and interest for unusual hotels. The survey was conducted in several cities, and respondents were selected randomly. For analysis we used 500 valid questionnaires.

\section{The survey results}

In south-eastern part of Europe unusual hotels aren't represented by a number that is appropriate in relation to the rest of Europe and some other parts of the world. However, we can point out some. Of the countries of South Eastern Europe, it seems that Slovenia is leading in development of this type (not just the hotel) accommodation - Hotel Breza, Tresor Hostel, Hostel Celica, Adrenalin Check Eco-camp. On the territory of Romania, there are a number of old castles, most of them were turned into museums, but some operate as hotels - Ice Hotel, Dracula Castle. Croatia offers the possibility of accommodation in one of the many lighthouses along the coast line and the evidence that this trend of unusual hotel coming to this country is the planned construction of a rotating hotel on the island of Šolta (Struga, Big Rat, Sušac, Savudria, St. Peter, Gjalski Castle). In addition to these, we should mention the Austrian (Das Park Hotel, Rogner Bad Blumau and Schneedorf), Greek (New Hotel, Amaliada Treehouse) and Hungarian hotels (Aquamarina Boat Hotel, Héderváry Castle).

As stated before, global survey conducted by e-mail to the unusual hotels around the world was not entirely successful (from a statistical point of view), but the data obtained should not be dismissed, and they will be displayed. Hotels that have provided the required information were: V8 Hotel (Germany), Hans Brinker Hotel (Netherlands), Dog Bark Park Inn (USA), Palacio de Sal Hotel (Bolivia), Crazy House (Vietnam), Kumbuk River (Sri Lanka), Earthship Biotecture (USA), Controversy Hotel (Netherlands), Free Spirit Spheres (Canada), Hotel Pelirocco (UK), Chole Mjini (Tanzania), Elqui Domos (Chile), Adrenalin Check (Slovenia), Kennedy School (USA), Jumbo Stay (Sweden), Heceta Head Lightstation (USA), Iglu-Dorf Hotel (Switzerland), Devon Windmills (UK), Kadir's Tree Houses (Turkey), Becham Cave (USA).

The first question was about the age structure of the tourists who visit the unusual hotels. The results show that guests are all of ages, but the most common guests are age group of 26 to 35 years. The guests are mostly domestic tourists (from country where the hotel is located). Regarding the length of stay, an average of 2.6 nights shows shorter retention (transient type of hotel).

The majority of surveyed unusual hotels don't offer any unusual services, mainly only environmental tours. However, two hotels offer something a little different. These are hotels Chole Mjini (Tanzania), which offer diving with sharks and hotel Pelirocco (England) where they organize discrete games for adults. 
The question concerning the length of existence of facilities shows that the average age is 11.5 years, which means that this type of hotel is relatively new phenomenon. Ideas for opening of surveyed objects are various and their occupation is $62 \%$ on average.

In Serbia, there are no unusual hotels in the true sense of the word. This type of hotel is still at its beginning, but some good examples in this direction are examples of hostel ArkaBarka (in Belgrade) or hotels Ečka (near Zrenjanin) and Fantast (near Bečej).

The basic socio-demographic data about the respondents are shown in Figure 1.

Approximately $42 \%$ of respondents preferred holiday spent in Serbia, while $58 \%$ rather decide to go abroad.

The following questions were related to tourist opinion about unusual hotels. Most respondents $(73 \%)$ were familiar with the term "unusual hotel", but only $13 \%$ said they stayed in a hotel

\section{Gender}

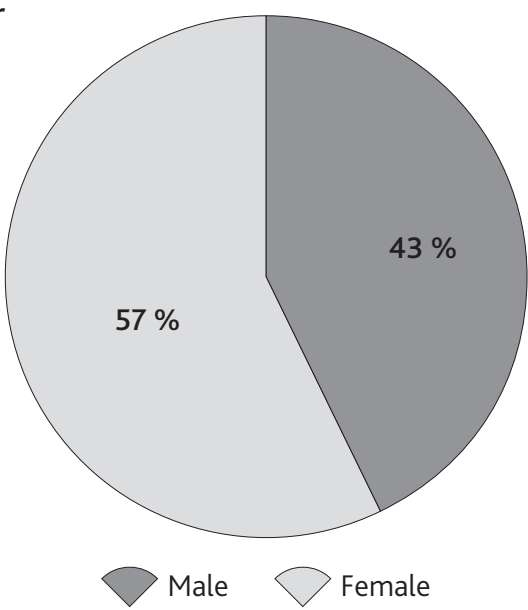

Level of education

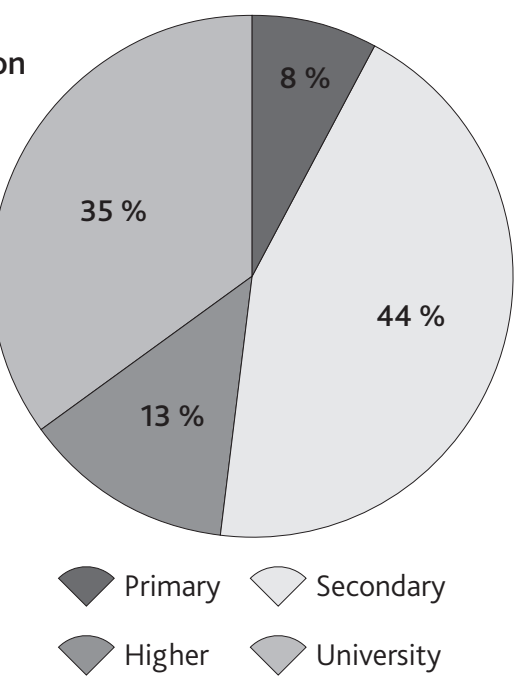

Age

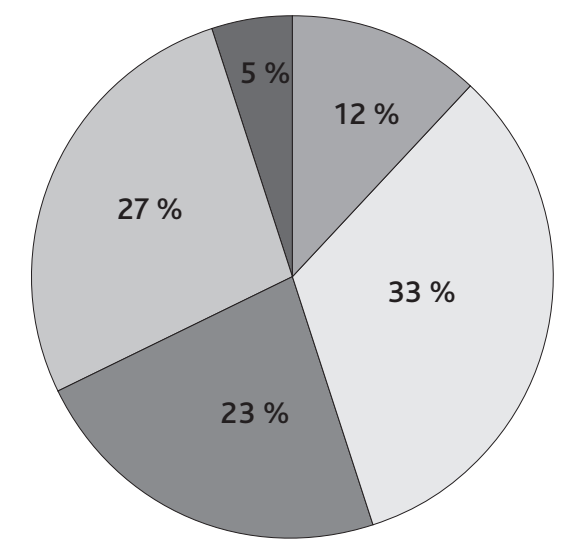

20 or less $>21$ to 35 36 to 50 51 to 75 more than 75

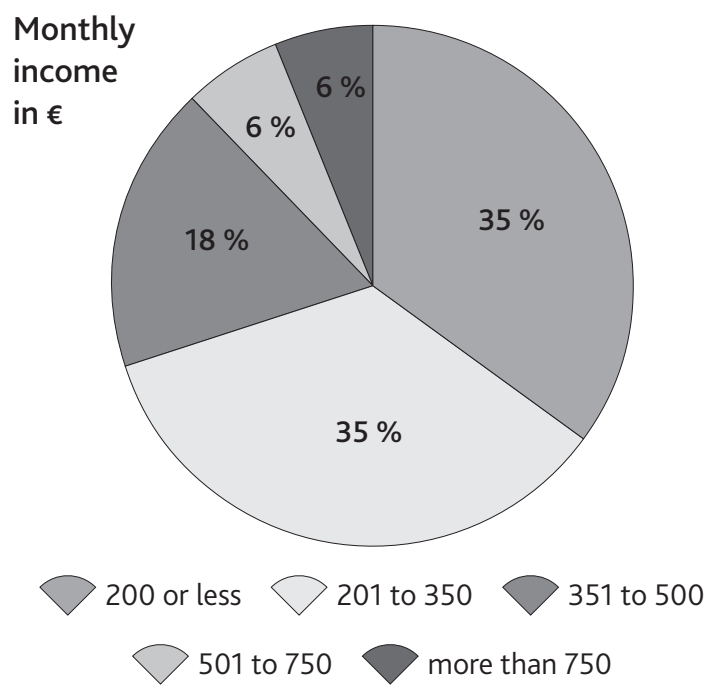

Figure 1. Socio-demographic characteristics of respondents 
that could be considered unusual. It is completely contrary situation with the mood of the respondents to visit or stay in some of unusual hotels ( $87 \%$ pro : $13 \%$ contra). According to the survey, unusual hotels that tourists would prefer to visit (if they are able to) are underwater hotels, chocolate hotels, old castles hotels, ice hotels. There were also those who would be visited any unusual hotel.

The positive attitude that the opening of this type of hotel in Serbia would contribute to the development and recognition of Serbian tourism, have an absolute majority of respondents $(85 \%)$. In potential situation that they could invest in the construction of unusual hotels, approximately $54 \%$ of tourists would decide to do so, while $46 \%$ opposed.

Respondents expressed their creativity through giving their own ideas for unusual hotel. The majority (64\%) did not have a response, while some have interesting ideas. Some of the most original are Prehistoric hotel, Barbie hotel, Volcano hotel, Parliament hotel, Horror hotel, Hotel in the White House and Candy hotel.

For the purposes of research correlation analysis of socio-demographic indicators and some answers to the questions was conducted.

Table 1. Correlation analysis

\begin{tabular}{|c|c|c|c|c|c|c|}
\hline & & Gender & Age & $\begin{array}{l}\text { Level of } \\
\text { education }\end{array}$ & $\begin{array}{c}\text { Monthly } \\
\text { income in } €\end{array}$ & $\begin{array}{l}\text { Level of desire to } \\
\text { visit or stay in an } \\
\text { Unusual Hotel }\end{array}$ \\
\hline \multirow{3}{*}{ Gender } & Pearson Correlation & 1 & -.107 & .201 & -.059 & -.223 \\
\hline & Sig. (2-tailed) & & .270 & .057 & .545 & .080 \\
\hline & $\mathrm{N}$ & 500 & 500 & 500 & 500 & 500 \\
\hline \multirow{3}{*}{ Age } & Pearson Correlation & -.107 & 1 & -.097 & .189 & .397 \\
\hline & Sig. (2-tailed) & .270 & & .317 & .149 & .105 \\
\hline & $\mathrm{N}$ & 500 & 500 & 500 & 500 & 500 \\
\hline \multirow{3}{*}{ Level of education } & Pearson Correlation & .201 & -.097 & 1 & .118 & $-.558 * *$ \\
\hline & Sig. (2-tailed) & .057 & .317 & & .223 & .007 \\
\hline & $\mathrm{N}$ & 500 & 500 & 500 & 500 & 500 \\
\hline \multirow{3}{*}{$\begin{array}{l}\text { Monthly income } \\
\text { in EUR }\end{array}$} & Pearson Correlation & -.059 & .189 & .118 & 1 & $.306 * *$ \\
\hline & Sig. (2-tailed) & .545 & .149 & .223 & & .000 \\
\hline & $\mathrm{N}$ & 500 & 500 & 500 & 500 & 500 \\
\hline \multirow{3}{*}{$\begin{array}{l}\text { Level of desire to } \\
\text { visit or stay in an } \\
\text { Unusual Hotel }\end{array}$} & Pearson Correlation & -.223 & .397 & $-.558 * *$ & $.306 * *$ & 1 \\
\hline & Sig. (2-tailed) & .080 & .105 & .007 & .000 & \\
\hline & $\mathrm{N}$ & 500 & 500 & 500 & 500 & 500 \\
\hline
\end{tabular}

*. Correlation is significant at the 0.05 level (2-tailed).

**. Correlation is significant at the 0.01 level (2-tailed).

The results showed, as might suggest, that level of education and desire to visit or stay in an unusual hotel had a statistically significant positive relationship which is strong. Also, the monthly income and the decision to visit or stay at some of unusual hotels had a statistically significant positive relationship, which however was not strong. 


\section{Discussion}

The development of unusual hotel is linked to the development of tourism. Tourism development would not have been possible without the development of the hotel industry, just as the hotel industry would have no purpose without the development of tourism. The hotel industry makes the material basis of tourism.

Tourists have become more experienced so their travel needs become more complex. They have desire to visit new locations, and receive non-standard and atypical services. This of course primarily relates to hotel industry. Hotels have had to adapt to the needs of demanding tourists. Stereotypical product that includes accommodation, food and drink, simply was no longer enough. Today, automation and rapid development of technology are ubiquitous trend. Knowledge and information are highly appreciated, as well as environmental protection and health, all of which affect the life of tourists. This style is projected on a trip. Therefore, it is necessary to customize hotels according to specific types of tourists. The result of this adjustment, among others, is the development of unusual hotels. The appearance of this type of hotels shows a high degree of hospitality customization, even when it comes to extreme forms of tourism. This indicates that hotel industry of the future will be able to follow the demands of tourists, however they seemed impossible. This is supported by the current realization of hotel projects in space. Because of all this hospitality companies have to follow the trends in tourism and to adapt to meet the demands of consumers.

Around the world unusual hotels have taken a recognizable place. This type of hotel is particularly pronounced in Europe (northern and western part) and North America. This points to innovation and monitoring of tourism trends in these regions, as well as a higher level of development of hotel industry. Tourists need the opportunity for new experiences and adventures that will be long remembered, exactly what these hotels provide. This trend in the world encourages thinking and creativity which is certainly positive.

While moving towards Serbia, the general impression is that the number of unusual hotels declines. Thus, in the neighbouring countries one can found only a small number of these facilities. However, even this small number shows that hoteliers are aware of the need for change. The economic situation affects the overall development of society and economy, and consequently the hotel industry development. It is therefore not surprising that Slovenia, as the most developed country of the former Yugoslavia republics has the largest number of these facilities. Like other global and European trends, it is clear that attention has been focused on this one.

What is very surprising is the small number of unusual hotels in the highly developed tourist country what is Croatia. The situation is similar in Montenegro while for Macedonia, Bosnia and Herzegovina and Bulgaria there were no information about the existence of unusual hotels. Perhaps that is what these countries need in order to improve the tourist offer and increased the number of tourists. In other neighboring countries (Hungary, Romania, Greece), there is progress on this issue, while Austria is far ahead of all the above.

When it comes to unusual hotels in Serbia there is only one facility that the world's most popular web sites that deal with unusual hotels have included in their offer. It is Arkabarka hostel in Belgrade. While in somewhat unusual location on the river, the hostel still has no elements of eccentricity like unusual hotels in the world. Of the others, there are hotels in the old castles, where the list of this type of accommodation in Serbia ends. The majority of respondents had never visited any unusual hotel, but most would gladly do so, showing the will and interest. However, the attitudes of the respondents speak of mistrust in the success of this concept here and now and, to some extent, negligence of the need for new ideas. The reason is 
that benefits of the functioning of unusual hotels have not yet been recognized, such as country popularizing in foreign media reports, increased choice of accommodation, facilities that attract domestic and foreign tourists etc Serbia lacks of investment in many areas, as well in this. The development of an unusual type of hotel would undoubtedly improve Serbian tourism offer and increase number of tourists.

\section{Conclusion}

Unusual hotels were created in response to the complex demand of modern tourists, but this type of accommodation is not developed equally in all parts of the world.

Specifically, in Serbia, there is almost none, but with a good idea for such type of accommodation it could be good business opportunity (such as imaginatively-themed hotel, the historical-religious, eco hotels or tree houses). However, so far there are no investors who would provide the opportunity for such projects. Perhaps such trend in Serbia is consequence of the lack of funds and the crisis in last few years.

Unusual hotels are not fully understood as a phenomenon, although they may have a great impact on the tourism of the country where they are located. This research has shown a high level of interest of tourists for development of this type of accommodation. They recognize the importance of the existence of unusual hotel as a comparative advantage over other destinations. Investors should take advantage of this.

\section{References}

Dalbor, M., Upneja, A. 2004. The Investment opportunity set and the long-term debt decision of U.S. lodging firms, Journal of Hospitality \& Tourism Research 28 (3), 346-355.

Doswell, R., Nailon, P. (1976). Further Case Studies in Hotel Management, Barrie and Jenkins, London

Gray, B.J., Matear, S.M., Matheson, P.K. 20oo. Improving the performance of hospitality firms, International Journal of Contemporary Hospitality Management 12 (3), 149-155.

Hakan, V. E., Jamel, C. 2006. Relationship between leadership power bases and job stress of subordinates: example from boutique hotels, Management Research News 29 (5), 285 - 297.

Janicevic, S. (2008). Hospitality Service with service techniques, equipment and inventory, Faculty of Science, Department of Geography, Tourism and Hotel Management, Novi Sad.

Keiser, J.D. 1998. Hospitality and tourism: a rhetorical analysis and conceptual framework for identifying industry meanings, Journal of Hospitality \& Tourism Research 22 (2), 115-128.

Kosar, Lj. (2008). Hotel Industry I, The College of hotel management, Belgrade.

Kosar, Lj. (2008). Hotel Industry II, The College of hotel management, Belgrade.

Kosar, Lj. 2007. Adapting of Hotel Industry to contemporary forms of tourism, Turizam 11, $10-13$.

Liana, V., Rohit, V., Gerhard, P., Chekitan, D. 2005. Service innovation and customer choices in the hospitality industry, Managing Service Quality 15 (6), 555 - 576.

Mandy, A. 2007. What has influenced growth in the UK's boutique hotel sector?, International Journal of Contemporary Hospitality Management 19 (2), $169-177$.

Middleton, T. V. C. (1988). Marketing in Travel and Tourism, Heinemann, London 
Wai, M. L., Mel, E. 2009. Elucidating the aesthetic and operational characteristics of UK boutique hotels, International Journal of Contemporary Hospitality Management 21 (1), $38-51$. Walterspiel, A. (1952). My Future is Kitshen and Restaurant, Eigenverlag, Süddeutscher Verlag, Deutscher Taschenbuch-Verlag.

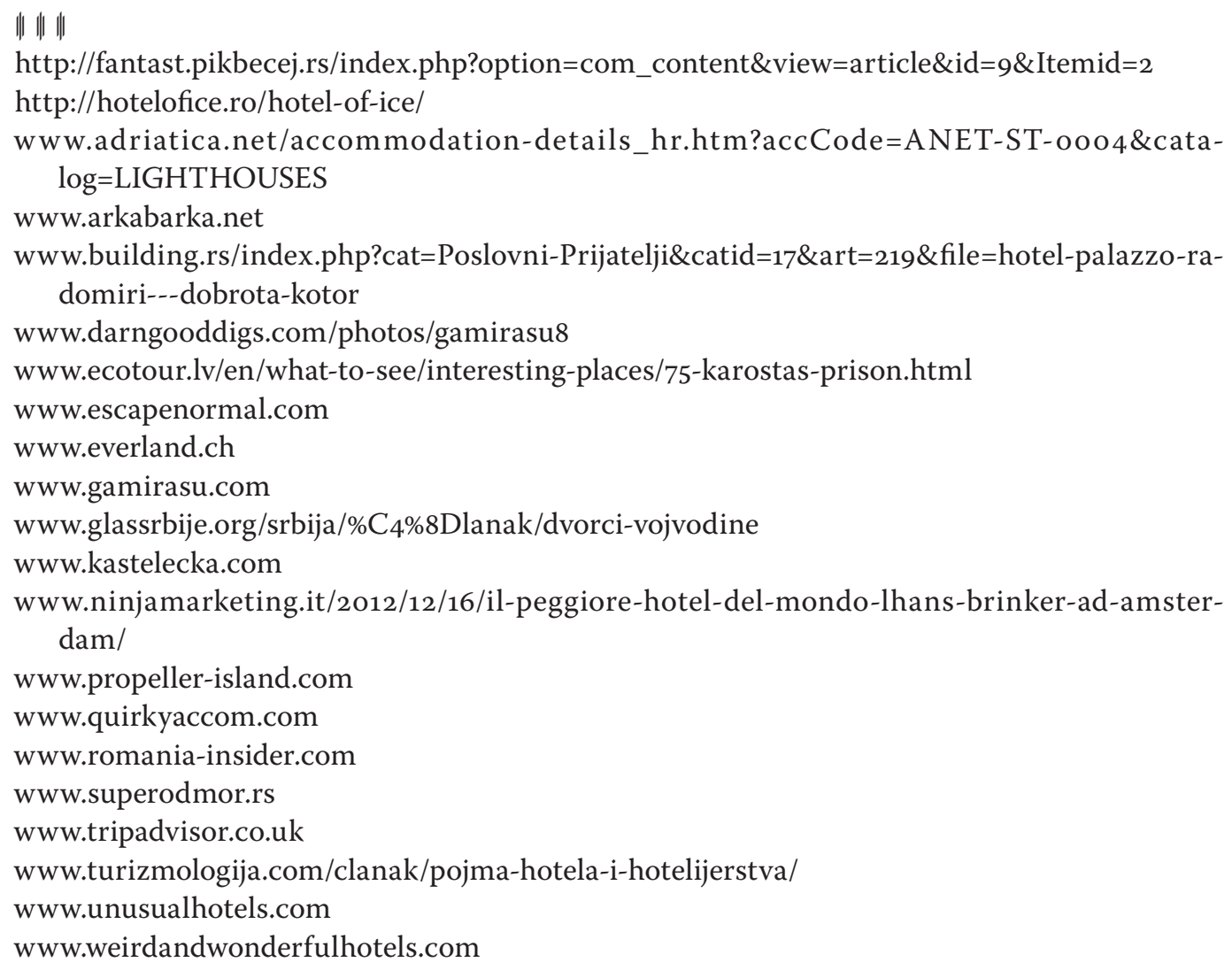

